Purdue University Purdue e-Pubs

$10-27-2010$

\title{
Performance of Vapor Compression Systems with Compressor Oil Flooding and Regeneration
}

Ian H. Bell

Purdue University

Eckhard A. Groll

Purdue University

James E. Braun

Purdue University

Follow this and additional works at: http://docs.lib.purdue.edu/herrick

Bell, Ian H.; Groll, Eckhard A.; and Braun, James E., "Performance of Vapor Compression Systems with Compressor Oil Flooding and Regeneration" (2010). Publications of the Ray W. Herrick Laboratories. Paper 4.

http://docs.lib.purdue.edu/herrick/4

This document has been made available through Purdue e-Pubs, a service of the Purdue University Libraries. Please contact epubs@purdue.edu for additional information. 


\title{
Performance of Vapor Compression Systems with Compressor Oil Flooding and Regeneration
}

\author{
I. Bell ${ }^{\mathrm{a}, *}$, E. Groll ${ }^{\mathrm{a}}$, J. Braun ${ }^{\mathrm{a}}$ \\ ${ }^{a}$ Purdue University Department of Mechanical Engineering, 140 S. Martin Jischke Drive, West Lafayette, IN, 47906
}

\begin{abstract}
Vapor compression refrigeration technology has seen great improvement over the last several decades in terms of cycle efficiency through a concerted effort of manufacturers, regulators, and research engineers. As the standard vapor compression systems approach practical limits, cycle modifications should be investigated to increase system efficiency and capacity. One possible means of increasing cycle efficiency is to flood the compressor with a large quantity of oil to achieve a quasi-isothermal compression process, in addition to using a regenerator to increase refrigerant subcooling.

In theory, compressor flooding and regeneration can provide a significant increase in system efficiency over the standard vapor compression system. The effectiveness of compressor flooding and regeneration increases as the temperature lift of the system increases. Therefore, this technology is particularly well suited towards lower evaporating temperatures and high ambient temperatures as seen in supermarket refrigeration applications. While predicted increases in cycle efficiency are over $40 \%$ for supermarket refrigeration applications, this technology is still very beneficial for typical air-conditioning applications, for which improvements in cycle efficiency greater than $5 \%$ are predicted. It has to be noted though that the beneficial effects of compressor flooding can only be realized if a regenerator is used to exchange heat between the refrigerant vapor exiting the evaporator and the liquid exiting the condenser.
\end{abstract}

Key words:

Air conditioning, Refrigeration, Regeneration, Flooding, High Efficiency, Flooded Compression

\section{Nomenclature}

$\begin{array}{ll}c_{p} & \text { Specific heat }\left(\mathrm{kJ} \mathrm{kg}^{-1} \mathrm{~K}^{-1}\right) \\ C O P & \text { Coefficient of performance } \\ \dot{E} & \text { Rate of irreversibility generation }(\mathrm{kW}) \\ h & \text { Enthalpy }\left(\mathrm{kJ} \mathrm{kg}^{-1}\right) \\ \Delta h & \text { Difference in enthalpy }\left(\mathrm{kJ} \mathrm{kg}^{-1}\right) \\ \dot{m} & \text { Mass flow rate }\left(\mathrm{kg} \mathrm{s}^{-1}\right) \\ s & \text { Entropy }\left(\mathrm{kJ} \mathrm{kg}{ }^{-1} \mathrm{~K}^{-1}\right) \\ p & \text { Pressure }(\mathrm{kPa}) \\ T & \text { Temperature }\left(\mathrm{K},{ }^{\circ} \mathrm{C}\right) \\ \Delta T & \text { Difference in temperature }(\mathrm{K}) \\ \dot{Q} & \text { Heat transfer rate }\left(\mathrm{kW}^{-1}\right) \\ v & \text { Specific volume }\left(\mathrm{m}^{3} \mathrm{~kg}^{-1}\right) \\ \dot{W} & \text { Power (kW) } \\ x & \text { Mass flow rate fraction (mass } \%) \\ \varepsilon & \text { Effectiveness of regenerator } \\ \eta & \text { Adiabatic efficiency }\end{array}$

\section{Subscripts}

$\begin{array}{ll}1,2,3, \ldots & \text { State point } \\ 1 m, 2 m, 3 m, \ldots & \text { Mixture property at state point } \\ 0 & \text { Reference } \\ \text { comp } & \text { Compressor } \\ \text { cond } & \text { Condenser } \\ \text { crit } & \text { Critical property of refrigerant } \\ \text { evap } & \text { Evaporation } \\ \text { exp } & \text { Hydraulic Expander } \\ G & \text { Gas } \\ \text { L } & \text { Liquid } \\ \text { max } & \text { Maximum } \\ \text { mixer } & \text { Mixer } \\ \text { oil-cooler } & \text { Oil cooler } \\ \text { pinch } & \text { Heat exchanger approach } \\ \text { reg } & \text { Regenerator } \\ \text { sep } & \text { Separator } \\ \text { sh } & \text { Superheat } \\ \text { sink } & \text { Hot thermal reservoir } \\ \text { source } & \text { Cold thermal reservoir }\end{array}$

\footnotetext{
*Corresponding Author

Email addresses: ibell@purdue.edu (I. Bell), groll@purdue.edu (E. Groll), jbraun@purdue.edu (J. Braun)
} 


\section{Introduction}

From consideration of the polytropic compression process of an ideal gas, it is readily seen that the compression process which minimizes the gas specific work is an isothermal compression process where the heat of compression is removed from the gas during the compression process. Isothermal compression is the ultimate goal of thermal engineers, but challenging to achieve in practice. A number of means have been proposed to achieve isothermal compression, including cooling the compressor during the compression process (Kim et al., 2008).

One of the most promising means of achieving quasiisothermal compression is the addition of a large amount of high specific heat fluid to the refrigerant flow to absorb the heat of compression of the refrigerant. In practice, lubricity considerations would almost certainly require that the fluid be liquid oil, but other fluids are possible. Hugenroth et al. (2006; 2006) have extensively studied liquid flooding in order to approximate the Ericsson cycle, and also showed from simplified compressor modeling that the ideal flooding liquid was water due to its low specific volume and high specific heat. The low specific volume is beneficial since the liquid must be pumped to the discharge pressure of the compressor along with the refrigerant and a low specific volume minimizes the specific compression work of the liquid. In addition, with a high liquid specific heat, less liquid is required to absorb the same amount of heat from the compression process.

Other methods have been proposed to cool the compressor during the compression process, including refrigerant vapor and liquid refrigerant injection (Winandy and Lebrun, 2002). When considering the limit of an infinite number of injection points, the compression process can follow along the saturated vapor curve, and the increases in system efficiency can be significant(Mathison et al., 2011).

In the last few decades, a number of screw compressor researchers have investigated flooding with oil in order to improve the sealing of the compressor(Bein and Hamilton, 1982; Li and Jin, 2004; Huagen et al., 2004; Fujiwara and Osada, 1995; Tang and Fleming, 1992; Stosic et al., 1990; Wu and Jin, 1988; Stosic et al., 1988; Blaise and Dutto, 1988; Singh and Patel, 1984). However, the oil flow rates to achieve proper sealing are significantly lower than the oil flow rates proposed here. Recently a number of authors have applied oil flooding to refrigerant scroll compressors (Hiwata et al., 2002; Sakuda et al., 2001), for which some positive results have been found. However, the compressors that were used were not optimized for flooded compression.

The literature on the details of a combined compression of refrigerant and pumping of liquid process is quite limited. However, there has been some recent detailed mechanistic modeling of the liquid-flooded compression and expansion processes in scroll compressors and expanders, respectively, (Bell et al., 2008a,b; Lemort et al., 2008) from which a thorough understanding of the impact of oil has been obtained.

The only prior work in open literature which deals with the cycle modeling of vapor compression systems with oil flooding is that of Hugenroth et al. (2007), though their analysis did not take into account the possibility of adding a regenerator to the system.

\section{Flooded Compression}

The technology of flooded vapor compression is based on a standard vapor-compression cooling cycle. Figure 1 shows the standard four-component vapor compression cycle which is modified to add a regenerator and an oilprocessing circuit. In this configuration, oil and refrigerant vapor are mixed adiabatically prior to injection into the compressor, and then are compressed together in the compressor from state point 1 to state point 2 . After exiting the compressor, the two-phase mixture of liquid and refrigerant vapor enters the high-pressure separator at state point 2, and fully-separated oil and refrigerant vapor streams exit the separator at state points 9 and 3, respectively. The oil and refrigerant are cooled in parallel circuits in the condenser/oil cooler to slightly above the heat sink temperature. The oil exiting the oil cooler at state point 10 is expanded back to state point 11, at which point it is mixed back into the refrigerant vapor exiting the regenerator at state point 8 . After being condensed in the condenser, the liquid refrigerant at state point 4 passes through a regenerator where it exchanges heat with the refrigerant vapor exiting the evaporator and the saturated liquid is sub-cooled. The sub-cooled refrigerant at state point 5 is throttled through the expansion device to state point 6 and then evaporated to exit the evaporator at state point 7 .

The baseline cycle defined for comparison with the flooded system is a standard four component vapor compression system with compressor, condenser, expansion valve, and evaporator. For a fair comparison between flooded and non-flooded systems, the same pinch temperature difference, subcooling and superheat are used. In addition, the compressor isentropic efficiency is the same, but the system operates without a regenerator and without any oil flooding.

As a result of flooded compression, the thermodynamic property plots for the refrigerant exhibit some unique features. Figure 2 compares the baseline cycle, shown with dashed lines, to the flooded cycle, shown with solid lines. Although the total mixture specific enthalpy increases as the gas-liquid mixture is compressed from low to high pressure, Figure 2 shows that the specific enthalpy of the gas actually decreases due to the oil's ability to absorb the heat of compression of the refrigerant vapor. Also, with the presence of the regenerator, the gas-liquid mixture will always enter the compressor at approximately the same amount above the ambient temperature. This is due to the fact that the oil is cooled in the oil cooler to near the hot reservoir temperature, and will always exit the oil 




Figure 1: Flooded compression system schematic

cooler at the same temperature by the assumption of a constant pinch temperature. By design, the capacitance flow rate of the oil is significantly higher than that of the gas, and the gas will take on the oil temperature during the mixing process.

\section{Cycle Modeling}

The modeling of flooded compression cycles is similar to that of standard, one-fluid, vapor compression systems. The primary differences are due to considering the oil and its properties during the compression process and in the oil loop. Several simplifying assumptions are utilized in order to evaluate the mixture properties. It is assumed that the oil and refrigerant are in thermal and mechanical equilibrium; thus both the oil and refrigerant phases are at the same temperature and pressure. Additionally, it is assumed that the phases exit the oil separator completely separated, i.e., there is no refrigerant dissolved in the oil stream or oil droplets carried in the refrigerant vapor stream. Effective separation of refrigerant and flooding agent, low solubility of refrigerant, and good lubricity in the compressor can be achieved by selection of the appropriate flooding agent. From a simplified thermodynamic analysis carried out by Bell et al. (2010b), it is shown that refrigerant solubility in the flooding agent in the separator has a deleterious impact on overall system capacity and efficiency, but these effects are not considered here as they are relatively small for solubility fractions on the order of a few percent.

For the cycle analysis, the necessary thermodynamic mixture properties are the mixture enthalpy and mixture entropy as functions of temperature and pressure. Assuming homogeneous mixtures, the mixture enthalpy and mixture entropy can be expressed as a function of temperature, pressure and oil mass flow fraction as

$$
\begin{aligned}
& h_{m}\left(T, p, x_{L}\right)=x_{L} h_{L}+\left(1-x_{L}\right) h_{G} \\
& s_{m}\left(T, p, x_{L}\right)=x_{L} s_{L}+\left(1-x_{L}\right) s_{G}
\end{aligned}
$$

which is simply an oil-mass-flow-fraction weighted average of the properties of the separated oil and gas phases evaluated at the given temperature and pressure. The oil mass flow fraction, $x_{L}$, is given as the ratio of the mass flow rates of oil to the total mass flow rate, defined by

$$
x_{L}=\frac{\dot{m}_{L}}{\dot{m}_{L}+\dot{m}_{G}}
$$

The below system of equations shown in this section is implemented in MATLAB (Mathworks, 1994-2009) and the refrigerant thermodynamic properties are provided through a link with Refprop 7.0 (Lemmon et al., 2002). The oil considered in this analysis is a polyalkyl glycol (PAG) oil 0-OB-1020 whose properties are obtained from Booser (1997). The specific heat and density data are fit with linear curves as a function of temperature, and shown here for reference

$$
\begin{aligned}
& c_{p, L}=0.00274374 \cdot T+1.08646 \\
& \rho_{L}=-0.726923 \cdot T+1200.33
\end{aligned}
$$

where $c_{p, L}, \rho_{L}$ and $T$ are in units of $\mathrm{kJ} \mathrm{kg}^{-1} \mathrm{~K}^{-1}, \mathrm{~kg} \mathrm{~m}^{-3}$, and ${ }^{\circ} \mathrm{C}$ respectively.

While the analysis permits the addition of a hydraulic expander to capture some of the work of compression of the oil, the first analysis uses a simple throttling valve to expand the oil back to the compressor suction pressure, implemented computationally by using a hydraulic expander isentropic efficiency of 0.0. The nominal parameters in Table 1 were used unless otherwise stated. In addition, it is assumed that the pressure drop irreversibilities in the flooding liquid loop can be neglected since appropriate component sizing should result in low pressure drops. In addition, the length of tube that the liquid must be pumped through is relatively small since all the flooding liquid will reside in the condensing unit.

\subsection{Compressor}

In the compressor, a mixture of oil and gas is compressed from the suction pressure to the condensing pressure. A 



Figure 2: Flooded compression pressure-enthalpy and temperature-entropy plots of the refrigerant(Dashed lines: baseline cycle)

Table 1: Nominal values used in modeling

\begin{tabular}{cc}
\hline \hline Parameter & Value \\
\hline$\dot{m}_{G}[\mathrm{~kg} / \mathrm{s}]$ & 1 \\
$\Delta T_{\text {pinch }}\left[{ }^{\circ} \mathrm{C}\right]$ & 5 \\
$\Delta T_{\text {sub }}\left[{ }^{\circ} \mathrm{C}\right]$ & 1.0 \\
$\Delta T_{\text {sh }}\left[{ }^{\circ} \mathrm{C}\right]$ & 1.0 \\
$\eta_{\text {comp }}[-]$ & 0.7 \\
$\eta_{\text {exp }}[-]$ & 0.0 \\
$\epsilon_{\text {reg }}[-]$ & 0.9 \\
$T_{0}[\mathrm{~K}]$ & 298 \\
\hline \hline
\end{tabular}

constant compressor isentropic efficiency, defined based on mixture properties, is taken for the compressor. The experimental work of Bell et al. (2008a) investigated oilflooding in an off-the-shelf automotive scroll compressor operating with nitrogen as the refrigerant. They showed that the isentropic efficiency of the compressor decreases monotonically with an increase in oil mass flow fraction. Subsequent optimization of the scroll compressor with oil flooding has been carried out, and the results suggest that a high isentropic efficiency with high oil mass fractions can still be achieved (Bell et al., 2010a). The equations used to model the compressor are

$$
\begin{aligned}
& h_{1 m}=h\left(T_{1}, p_{1}, x_{L 1}\right) \\
& s_{1 m}=s\left(T_{1}, p_{1}, x_{L 1}\right) \\
& h_{2 s m}=h\left(p_{2}, x_{L 2}, s_{1}\right) \\
& \eta_{c o m p}=\frac{h_{2 s m}-h_{1 m}}{h_{2 m}-h_{1 m}} \\
& \dot{W}_{c o m p}=\dot{m}_{m}\left(h_{2 m}-h_{1 m}\right) \\
& \dot{E}_{c o m p}=T_{0} \dot{m}_{m}\left(s_{2 m}-s_{1 m}\right)
\end{aligned}
$$

\subsection{Oil Separator}

The oil separator takes the two-phase mixture of oil and refrigerant vapor exiting the compressor and separates the oil and refrigerant vapor into disparate phases. It is assumed that there is no heat transfer or pressure drops, and thus, the oil separator is modeled by

$$
\begin{aligned}
& T_{3}=T_{9}=T_{2} \\
& p_{3}=p_{9}=p_{2} \\
& x_{L 3}=0 \\
& x_{L 9}=1 \\
& \dot{E}_{\text {sep }}=0
\end{aligned}
$$

\subsection{Condenser}

The condenser takes the dry, superheated refrigerant vapor exiting the separator and condenses it to subcooled liquid, or in the case of supercritical carbon dioxide, cools it to the gas cooler outlet temperature at constant pressure.

$$
\begin{aligned}
& T_{4}=T_{\text {sink }}+\Delta T_{\text {pinch }} \\
& h_{4}= \begin{cases}h_{\text {sat }}\left(T_{4}, x=0\right) & p_{4}<p_{\text {crit }} \\
h\left(p_{4}, T_{4}\right) & p_{4}>p_{\text {crit }}\end{cases} \\
& \dot{Q}_{\text {cond }}=\dot{m}_{G}\left(h_{4}-h_{3}\right) \\
& \dot{E}_{\text {cond }}=T_{0}\left[\dot{m}_{G}\left(s_{4}-s_{3}\right)-\frac{\dot{Q}_{\text {cond }}}{T_{\text {sink }}}\right]
\end{aligned}
$$

\subsection{Oil Cooler / Hydraulic Expander}

In the oil cooler, the hot oil exiting the oil separator is cooled back towards the sink temperature. After exiting the oil cooler, the oil is expanded back to the compressor suction pressure through a hydraulic expander. If a throttling valve is used in place of the hydraulic expander, the adiabatic efficiency of the expander can be taken to be equal to 0.0 . The oil cooler/hydraulic expander can be modeled by

$$
\begin{aligned}
& T_{10}=T_{\text {sink }}+\Delta T_{\text {pinch }} \\
& \dot{Q}_{\text {oil-cooler }}=\dot{m}_{L}\left(h_{9}-h_{10}\right) \\
& \dot{W}_{\text {exp }}=\eta_{\exp } v_{L}\left(p_{10}-p_{11}\right) \\
& \dot{W}_{\text {exp }}=\dot{m}_{L}\left(h_{10}-h_{11}\right) \\
& \dot{E}_{\text {exp }}=T_{0} \dot{m}_{L}\left(s_{11}-s_{10}\right)
\end{aligned}
$$




\subsection{Regenerator}

The regenerator allows for heat exchange between the refrigerant vapor exiting the evaporator and the liquid refrigerant exiting the condenser. This is a critical component of the oil flooding technology. It can be modeled by

$$
\begin{aligned}
& \Delta h_{r e g, \max }=\min \left\{\begin{array}{l}
h_{4}-h\left(T_{7}, p_{4}\right) \\
h\left(T_{4}, p_{7}\right)-h_{7}
\end{array}\right. \\
& \varepsilon=\frac{\Delta h_{r e g}}{\Delta h_{r e g, \max }} \\
& h_{5}=h_{4}-\Delta h_{r e g} \\
& h_{7}=h_{8}+\Delta h_{r e g} \\
& \dot{E}_{r e g}=T_{0} \dot{m}_{G}\left[\left(s_{8}+s_{5}\right)-\left(s_{4}+s_{7}\right)\right]
\end{aligned}
$$

\subsection{Evaporator/Expansion Valve}

The expansion valve throttles the sub-cooled refrigerant exiting the regenerator to the evaporator pressure. This refrigerant is then evaporated and exits the evaporator superheated at the evaporation pressure. The superheat is fixed for the evaporator, though it should be as close to zero as is practicable, to maximize internal heat exchange in the regenerator.

$$
\begin{aligned}
& T_{\text {evap }}=T_{\text {source }}-\Delta T_{\text {pinch }}-\Delta T_{\text {sh }} \\
& h_{7}=h\left(T_{\text {evap }}+\Delta T_{\text {sh }}, p_{\text {evap }}\right) \\
& \dot{Q}_{\text {evap }}=\dot{m}_{G}\left(h_{7}-h_{6}\right) \\
& \dot{E}_{\text {evap }}=T_{0}\left[\dot{m}_{G}\left(s_{7}-s_{6}\right)-\frac{\dot{Q}_{\text {evap }}}{T_{\text {source }}}\right]
\end{aligned}
$$

\subsection{Mixer}

Finally the oil and refrigerant streams are mixed back together at constant pressure, resulting in a mixture temperature approximately equal to the temperature of the oil exiting the oil cooler. This can be modeled by

$$
\begin{aligned}
& \dot{m}_{L} h_{11}+\dot{m}_{G} h_{8}-\left(\dot{m}_{L}+\dot{m}_{G}\right) h_{1 m}=0 \\
& \dot{E}_{\text {mixer }}=T_{0}\left[\left(\dot{m}_{L}+\dot{m}_{G}\right) s_{1 m}-\dot{m}_{G} s_{8}-\dot{m}_{L} s_{11}\right]
\end{aligned}
$$

\subsection{Cycle performance}

In order to characterize the the flooded and non-flooded systems, the system efficiency must be defined. The cycle efficiency, or Coefficient of Performance (COP) is defined with the typical definition

$$
C O P=\frac{\dot{Q}_{e v a p}}{\dot{W}_{c o m p}+\dot{W}_{e x p}}
$$

where for cycles operating with a throttling valve, the hydraulic expander power is zero.

\section{Flooding and the compression process}

For fixed heat source (cool space) and heat sink (ambient) temperatures as well as superheat, subcooling and pinch temperature differences, the suction pressure, suction temperature, and discharge pressure of the compressor are fixed. Therefore, the only free parameter affecting the compression power is the oil mass flow fraction. The oil flow rate impacts five irreversibility terms - the irreversibilities in the hydraulic expander, the irreversibilities in the compressor, the irreversibilities in the condenser (gas cooler in the case of supercritical $\mathrm{CO}_{2}$ ), the irreversibilities in the oil cooler, and the irreversibilities in the mixer. The decrease in irreversibilities in the condenser with oil flooding are due to the fact that the flooding decreases the condenser superheat horn and results in a lower condenser inlet temperature. For a R410A cooling cycle operating between source and sink temperatures of $5^{\circ} \mathrm{C}$ and $28^{\circ} \mathrm{C}$ respectively, the maximum system COP will be obtained for the oil mass flow fraction which minimizes the system irreversibilities. Figure 3 demonstrates that as the oil mass flow fraction increases, both the compressor and hydraulic expander irreversibilities increase since neither the compression or expansion of the oil proceeds isentropically, and more oil flow results in more irreversibility. Even though the oil helps to decrease the discharge temperature and approach an isothermal compression process, there is still an increase in compression irreversibility. The reason is that the oil still needs to be compressed in the compressor and the irreversibilities in the oil compression process are significant. On the other hand, the condenser irreversibilities are decreased since the desuperheating horn is reduced due to a more isothermal compression process. Typical oil mass flow fractions for non-flooded systems are on the order of a few percent or less.

The same methodology can be carried out for a wide range of refrigerants, and their optimum oil mass flow fraction can be found for a given operating condition. The optimum oil flow rate for a number of different refrigerants was determined by using the optimization toolbox in MATLAB. Figures 4 and 5 show the optimal oil mass flow fractions for sink temperatures of $28^{\circ} \mathrm{C}$ and $50^{\circ} \mathrm{C}$ respectively.

Considering the extreme cases of $\mathrm{CO}_{2}$ and ammonia, the distributions of component irreversibility are significantly different. This results in different optimum oil mass flow fractions. Figures 6 and 7 demonstrate the difference in optimal oil mass flow fraction for $\mathrm{CO}_{2}$ and ammonia. As seen in Table 2, the pressure difference between the high and low pressure sides for a $\mathrm{CO}_{2}$ cooling cycle operating subcritically is five times higher than for ammonia operating between the same reservoir temperatures. This pressure difference is even higher if the $\mathrm{CO}_{2}$ system high-side-pressure is supercritical. This has a very significant impact on the losses in the hydraulic expander and the compressor. Since for ammonia the pressure difference over the hydraulic expander is very small, the losses in the 


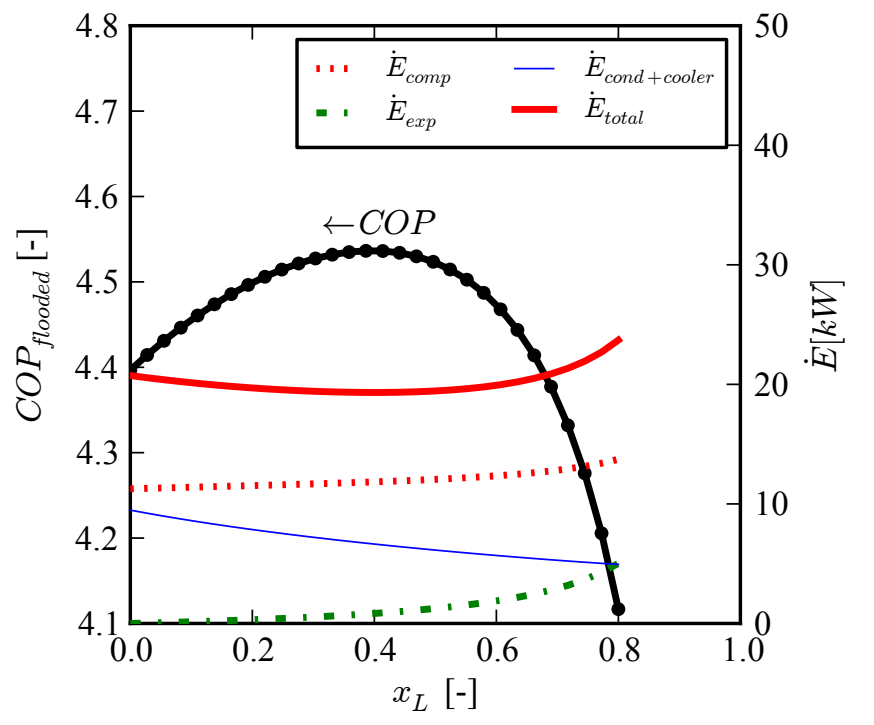

Figure 3: COP of oil flooded cycle and component irreversibilities for R410A ( $\left.\mathrm{T}_{\text {source }}=5^{\circ} \mathrm{C}, \mathrm{T}_{\operatorname{sink}}=28^{\circ} \mathrm{C}\right)$ as a function of oil mass flow fraction

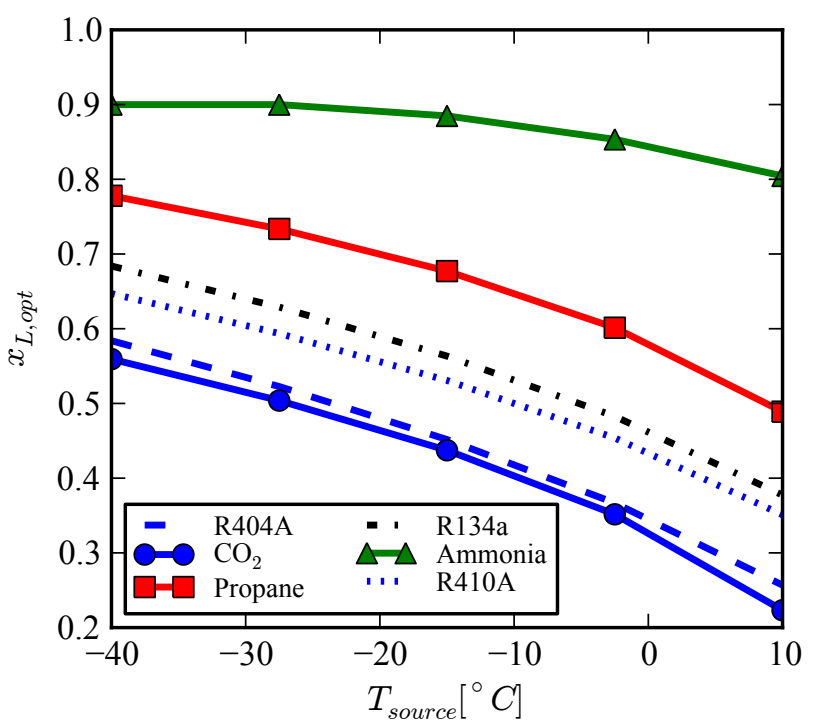

Figure 4: Optimum oil flooding rate for flooded system versus source temperature for $\mathrm{T}_{\sin k}=28^{\circ} \mathrm{C}$ for different refrigerants

ammonia cycle hydraulic expander are very small relative to the compressor irreversibilities. As a result, for a cycle operating with ammonia, the oil has a very small impact on the irreversibilities in the ammonia compressor and oil throttling valve due to the low pressure rise over the compressor. On the other hand, the losses in the $\mathrm{CO}_{2}$ cycle oil throttling valve are quite large relative to the compressor losses, and at oil mass flow fractions above $80 \%$ they are greater than the losses in the compressor. Therefore, replacing the oil throttle valve with a hydraulic expander for the $\mathrm{CO}_{2}$ cycle could be beneficial, as will be shown in the discussion on the hydraulic expander.

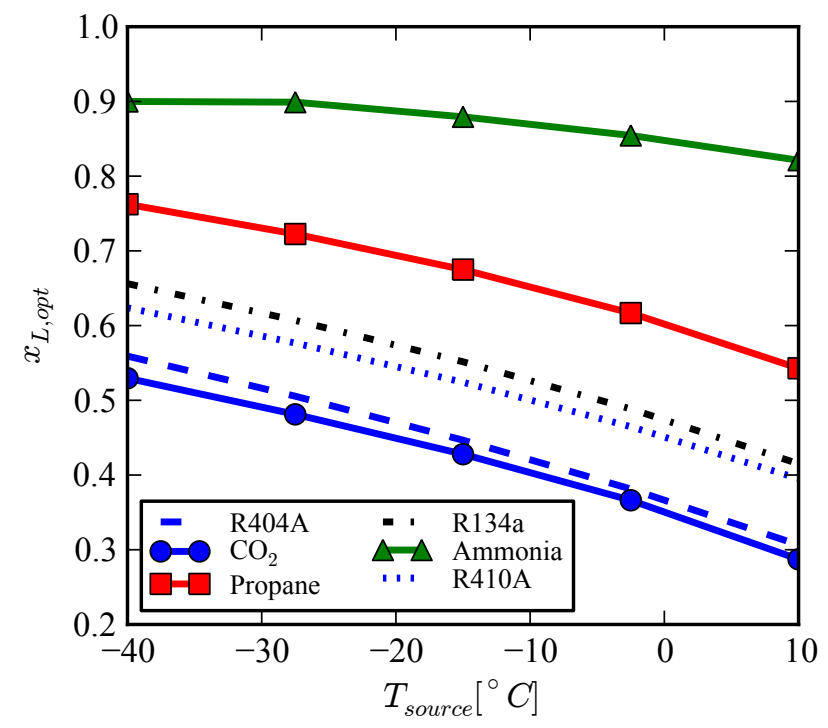

Figure 5: Optimum oil flooding rate for flooded system versus source temperature for $\mathrm{T}_{\operatorname{sink}}=50^{\circ} \mathrm{C}$ for different refrigerants

Table 2: Properties of working fluid in compression process (Compressor operating with $\mathrm{T}_{\text {evap }}=5^{\circ} \mathrm{C}, \Delta \mathrm{T}_{\text {sh }}=1^{\circ} \mathrm{C}, \mathrm{T}_{\text {cond }}=28^{\circ} \mathrm{C}$ )

\begin{tabular}{ccccc}
\hline \hline Fluid & $\rho$ & $\begin{array}{c}\mathrm{c}_{p} \\
\mathrm{~kg} / \mathrm{m}^{3}\end{array}$ & $\begin{array}{c}\mathrm{p}_{\text {ratio }} \\
\mathrm{kJg} / \mathrm{K}\end{array}$ & $\begin{array}{c}\Delta \mathrm{p} \\
\mathrm{kPa}\end{array}$ \\
\hline Ammonia & 4.096 & 2.741 & 2.131 & 583.6 \\
Propane & 11.92 & 1.833 & 1.863 & 475.7 \\
$\mathrm{R} 134 \mathrm{a}$ & 17.05 & 0.9185 & 2.079 & 377.4 \\
$\mathrm{R} 404 \mathrm{~A}$ & 35.45 & 0.9985 & 1.908 & 640.7 \\
$\mathrm{R} 410 \mathrm{~A}$ & 35.64 & 1.161 & 1.914 & 850.5 \\
$\mathrm{CO}_{2}$ & 112.9 & 2.056 & 1.736 & 2922 \\
\hline \hline
\end{tabular}

As the oil mass flow rate increases, a larger fraction of the heat rejection occurs in the oil cooler. For instance, for the transcritical $\mathrm{CO}_{2}$ flooded cycle shown in Figure 6, the percentage of heat rejection which occurs in the oil cooler is as much as $62.1 \%$ at an oil mass fraction of $90 \%$. Practical $\mathrm{CO}_{2}$ flooded systems would operate at lower oil mass fractions, and at the optimal oil mass fraction of $30 \%$, only $19 \%$ of the heat is rejected in the oil cooler. Some redesign of the heat rejection heat exchanger would be required to accommodate the additional area required for the oil cooling.

\section{Parametric Study}

In order to compare flooded and baseline performance, a baseline four-component cooling cycle with the operating parameters given in Table 1 was used. The cooled space $\left(T_{\text {source }}\right)$ and the ambient temperature $\left(T_{\text {sink }}\right)$ were fixed at the same value for both the flooded and baseline cycles for fair comparison. The same pinch temperature was used for all of the refrigerants, which is not necessarily a fair comparison since some of the working fluids selected 




Figure 6: COP of oil flooded cycle and component irreversibilities for $\mathrm{CO}_{2}\left(\mathrm{~T}_{\text {source }}=5^{\circ} \mathrm{C}, \mathrm{T}_{\text {sink }}=28^{\circ} \mathrm{C}\right)$ as a function of oil mass flow fraction

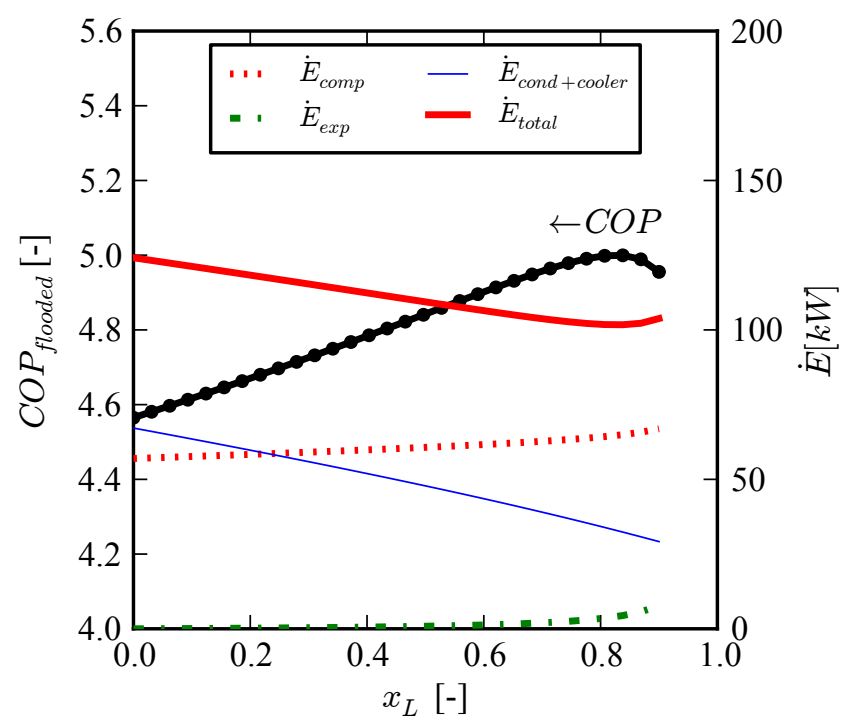

Figure 7: COP of oil flooded cycle and component irreversibilities for ammonia $\left(\mathrm{T}_{\text {source }}=5^{\circ} \mathrm{C}, \mathrm{T}_{\operatorname{sink}}=28^{\circ} \mathrm{C}\right)$ as a function of oil mass flow fraction

(namely carbon dioxide) have singularly good heat transfer characteristics and might be able to achieve lower pinch temperatures for the same heat exchanger size than the other refrigerants.

Most of the common refrigerants studied here have been analyzed in subcritical conditions, the only exception being carbon dioxide, which was always studied in a transcritical configuration. For carbon dioxide, the gas cooler pressure was determined by finding the gas cooler pressure which optimized the baseline cycle COP, and the same pressure was used for the flooded cycle.

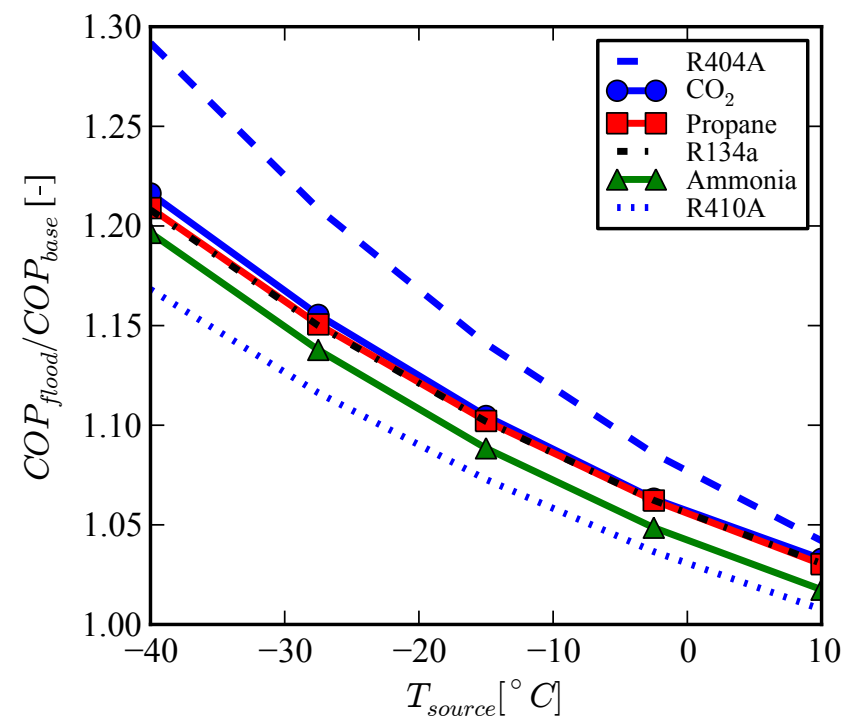

Figure 8: Ratio of flooded system to baseline system COP versus source temperature for $\mathrm{T}_{\sin k}=28^{\circ} \mathrm{C}$ for different refrigerants

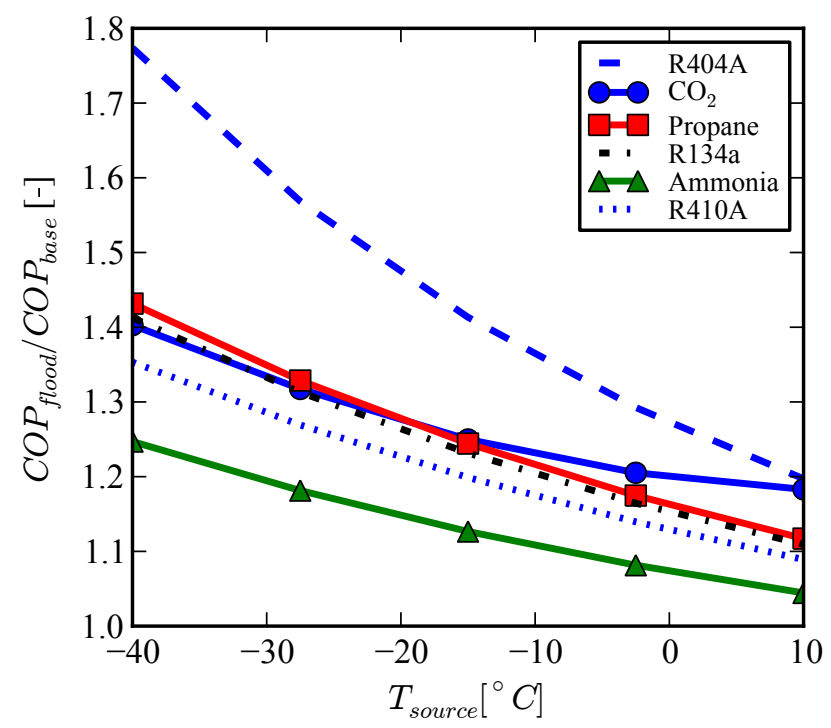

Figure 9: Ratio of flooded system to baseline system COP versus source temperature for $\mathrm{T}_{\operatorname{sink}}=50^{\circ} \mathrm{C}$ for different refrigerants

In order to have an equal comparison between refrigerants, properties of PAG oil were used as the flooding liquid for all of the refrigerants. In practical application, it is necessary that the liquid and the refrigerant are partially or wholly immiscible and insoluble since gravitational separation would generally be used to separate liquid and refrigerant. The optimal oil mass flow fraction was used in order to obtain the best performance for the flooded cycle.

Figures 8 and 9 show that the impact of oil flooding on system efficiency is dependent on working fluid selection and operating temperatures. Oil flooding is particularly beneficial for high heat-of-compression working fluids operating over large pressure ratios as they are prone to large 




Figure 10: Ratio of flooded to baseline system COP versus source temperature for varying regenerator effectiveness for $\mathrm{CO}_{2}\left(\mathrm{~T}_{\operatorname{sink}}=\right.$ $28^{\circ} \mathrm{C}$ )

compression and desuperheating losses. At lower source temperatures, the losses for the baseline cycle are predominantly throttling, compression and desuperheating losses. The flooding primarily decreases the desuperheating losses in the condenser, which is why the improvement in cycle performance is greatest at the lowest source temperatures.

The regenerator is a critical component of the flooded vapor compression system. Figure 10 shows that the efficiency of the flooded system is in fact worse than that of the baseline system as the regenerator efficiency approaches zero. This reduction in efficiency is due to the reduction in refrigerant subcooling prior to the expansion valve while the oil-vapor mixture entering the compressor is still quite superheated from mixing with the hot oil from the oil cooler. As a result, the compression power is higher, yet the cooling capacity is the same as the baseline system, resulting in worse efficiency. Figure 11 shows the impact on system performance of systems with and without $90 \%$ effective regenerators and optimal oil-flooding. These results show that both regenerator and oil flooding need to be utilized in concert in order to realize the full potential of oil flooding.

As shown above in Figure 7, the oil throttling losses for ammonia are quite minimal, which suggests that adding the capital cost of a hydraulic expander to the system would not be a good investment. On the other hand, the oil throttling losses for $\mathrm{CO}_{2}$ are larger due to the large pressure difference. When comparing the performance of three system configurations for $\mathrm{CO}_{2}$, namely the baseline system, a flooded system with an oil throttling valve, and a flooded system with a hydraulic expander with isentropic efficiency of $70 \%$, as shown in Figure 12, it is clear that the hydraulic expander has a relatively small effect. With the



Figure 11: Ratio of flooded to baseline system COP versus source temperature for systems with and without regenerator and oil flooding for $\mathrm{CO}_{2}\left(\mathrm{~T}_{\operatorname{sink}}=28^{\circ} \mathrm{C}\right)$

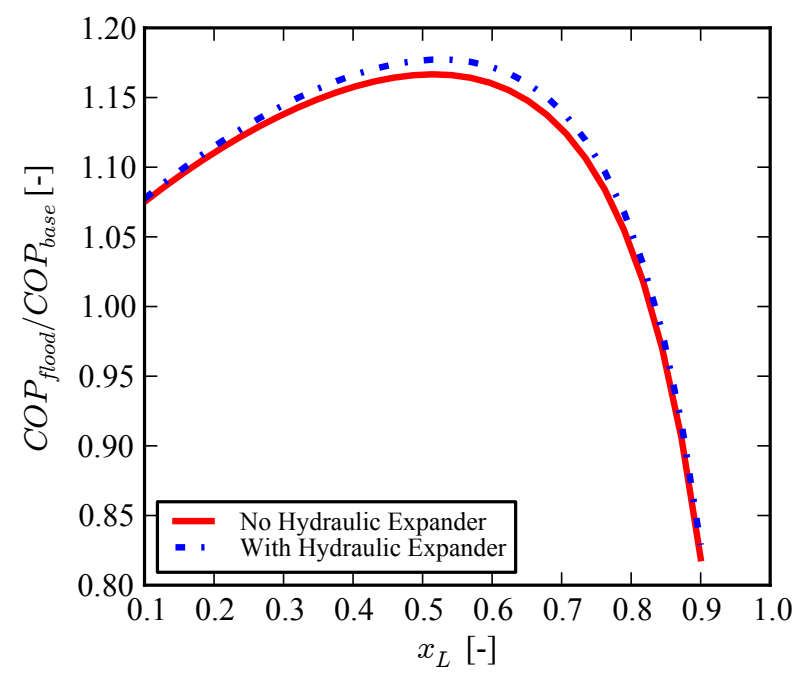

Figure 12: Ratio of flooded system to baseline system COP of flooded+throttling valve and flooded+expander systems versus oil mass flow fraction for $\mathrm{CO}_{2}\left(\mathrm{~T}_{\text {source }}=-30^{\circ} \mathrm{C}, \mathrm{T}_{\text {sink }}=28^{\circ} \mathrm{C}\right)$

addition of oil flooding and regeneration to a large temperature lift system, the COP increases by $16.7 \%$ above the baseline cycle, while with the addition of the hydraulic expander to the flooded system, the COP increases to $17.7 \%$ above the baseline cycle. The relatively weak impact of the hydraulic expander on cycle efficiency is due to the relatively small amount of power that is added to the oil in the compression process.

\section{Practical Considerations}

Typically, compressors are designed for a fairly small amount of oil circulation in order to lubricate the moving 
surfaces. Some compressor styles, such as reciprocating compressors, are not amenable to large amounts of oil injection. On the other hand, scroll compressors can readily handle large amounts of oil, as has been demonstrated by Hugenroth (2007), and Bell (2008a; 2008b). Therefore, the most significant challenge is to properly optimize the compressor design to handle large amounts of oil. The primary compressor design considerations are to give the oil a smooth flow path with few flow obstructions and to ensure that the suction and discharge ports are sufficiently large.

The design of the hydraulic expander is not considered challenging as there is a wide body of knowledge in the field of hydraulics which could be readily applied to this technology. In addition, the design of the oil separator is considered straight-forward as they are commonly used for screw compressors as well as in the chemical processing industry.

Otherwise, all other components of the cycle are standard off-the-shelf components for vapor compression systems which would require no modification. Thus, the amount of new design work required for this technology is considered fairly limited.

\section{Conclusion}

The addition of compressor flooding with regeneration in vapor compression systems results in a more isothermal compression process that can have a significant impact on system efficiency for large temperature lifts. Of the refrigerants considered, compressor flooding and regeneration has the greatest impact for R404A, and the least impact for ammonia. For refrigerants with large pressure differences across the compressor, the use of a hydraulic expander can also help to recapture some of the work of compression of the flooding liquid. The engineering challenges in implementation of this technology are reasonable, which suggests that it could be applied readily, either as retrofits or in new construction.

\section{Acknowledgment}

The authors of this paper would like to thank Prof. Galen King, Department of Mechanical Engineering, Purdue University, and Prof. Travis Horton, Department of Civil Engineering, Purdue University for their contributions to this paper.

\section{References}

Bein, T. W., Hamilton, J. F., 1982. Computer modeling of an oil flooded single screw air compressor. In: 1982 International Compressor Engineering Conference at Purdue University.

Bell, I., Groll, E., Braun, J., Horton, T., 2010a. Flooded compression in $\mathrm{CO}_{2}$ scroll compressors. In: 9th Gustav Lorentzen Conference on Natural Working Fluids, Sydney, Australia.
Bell, I., Groll, E., Braun, J., Horton, W., 2010b. Impact of Oil Solubility and Refrigerant Flashing on the Performance of Transcritical $\mathrm{CO}_{2}$ Vapor Compression Systems with Oil Flooding and Regeneration. In: 2010 International Refrigeration and Air Conditioning Conference at Purdue. No. 2148.

Bell, I., Lemort, V., Braun, J., Groll, E., 2008a. Analysis of LiquidFlooded Compression Using a Scroll Compressor. In: 19th International Compressor Engineering Conference at Purdue University. No. 1263.

Bell, I., Lemort, V., Braun, J., Groll, E., 2008b. Development of Liquid-Flooded Scroll Compressor and Expander Models. In: 19th International Compressor Engineering Conference at Purdue University. No. 1283.

Blaise, J., Dutto, T., 1988. Influence of oil injection and pressure ratio on single screw performances at high temperatures. In: 1988 International Compressor Engineering Conference at Purdue University.

Booser, E. R. (Ed.), 1997. Tribology Data Handbook. CRC Press.

Fujiwara, M., Osada, Y., 1995. Performance analysis of an oilinjected screw compressor and its application. Int. J. Refrig. 18, $220-227$.

Hiwata, A., Iida, N., Futagami, Y., Sawai, K., Ishii, N., 2002. Performance investigation with oil-injection to compression chambers on $\mathrm{CO}_{2}$-scroll compressor. In: 2002 Purdue Compressor Conference. No. C18-4.

Huagen, W., Ziwen, X., Pengcheng, S., 2004. Theoretical and experimental study on indicator diagram of twin screw refrigeration compressor. Int. J. Refrig. 27, 331-338.

Hugenroth, J., 2006. Liquid Flooded Ericsson Cycle Cooler. Ph.D. thesis, Purdue University.

Hugenroth, J., Braun, J., Groll, E., King, G., 2006. Oil Flooded Compression in Vapor Compression Heat Pump Systems. In: IHRIRHACE Conference. pp. 492-499.

Hugenroth, J., Braun, J., Groll, E., King, G., 2007. Thermodynamic analysis of a liquid-flooded Ericsson cycle cooler. Int. J. Refrig. 207, 331-338.

Kim, Y., Shin, D., Lee, J., 2008. A New Ericsson Cycle Comprising a Scroll Expander and a Scroll Compressor for Power and Refrigeration Applications. In: 2008 Compressor Engineering Conference at Purdue University. No. R022.

Lemmon, E., McLinden, M., Huber, M., 2002. Refprop 7.0. http://www.nist.gov/srd/nist23.htm.

Lemort, V., Bell, I., Groll, E., Braun, J., 2008. Analysis of liquidflooded expansion using a scroll expander. In: 2008 International Compressor Engineering Conference at Purdue University.

Li, H., Jin, L., 2004. Design optimization of an oil-flooded refrigeration single-screw compressor. In: 2004 International Compressor Engineering Conference at Purdue University. No. C077.

Mathison, M., Braun, J., Groll, E., 2011. Performance Limit for Economized Cycles with Continuous Refrigerant Injection. Int. J. Refrig. Submitted, In Review.

Mathworks, 1994-2009. MATLAB. http://www.mathworks.com/.

Sakuda, A., Sawai, K., Iida, N., Hiwata, A., Morimoto, T., Ishii, N., 2001. Performance improvement of scroll compressor with new sealing-oil supply mechanism. In: International Conference on Compressors and their Systems. No. C591/019.

Singh, P. J., Patel, G. C., 1984. A generalized performance computer program for oil flooded twin-screw compressors. In: 1984 International Compressor Engineering Conference at Purdue University.

Stosic, N., Kovacevic, A., Hanjalic, K., Milutinovic, L., 1988. Mathematical Modelling of the oil influence upon the working cycle of screw compressors. In: 1988 International Compressor Engineering Conference at Purdue University.

Stosic, N., Milutinovic, L., Hanjalic, K., Kovacevic, A., 1990. Experimental investigation of the influence of oil injection upon the screw compressor working process. In: 1990 International Compressor Engineering Conference at Purdue University.

Tang, Y., Fleming, J. S., 1992. Simulation of the Working Process of an oil flooded helical screw compressor with liquid refrigerant injection. In: 1992 International Compressor Engineering Conference at Purdue University. 
Winandy, E. L., Lebrun, J., 2002. Scroll compressors using gas and liquid injection- experimental analysis and modelling. Int. J. Refrig. 25, 1143-1156.

Wu, J., Jin, G., 1988. The Computer Simulation of oil-flooded single screw compressors. In: 1988 International Compressor Engineering Conference at Purdue University. 